\title{
Considerations on tinnitus retraining therapy and transcranial magnetic stimulation
}

\author{
Considerações sobre terapia de retreinamento de zumbido \\ e estimulação magnética transcraniana
}

\section{Consideraciones sobre la terapia de reentrenamiento del tinnitus y la estimulación magnética transcraneal}

\author{
Fernanda Santos Fernandes ${ }^{1}$, Carlos Eduardo Batista de Sousa ${ }^{2}$
}

\begin{abstract}
1.Fonoaudióloga, Mestre em Cognição e Linguagem, Universidade Estadual do Norte Fluminense Darcy Ribeiro (UENF). Docente do Curso de Fonoaudiologia do Centro Universitário Fluminense (UNIFLU), Campos dos Goytacazes-RJ. ORCID: https://orcid.org/0000-0002-1947-1553

2.Professor Doutor, Universidade Estadual do Norte Fluminense Darcy Ribeiro (UENF), Laboratório de Cognição e Linguagem, Programa de Pós-Graduação em Ciências Naturais e Programa de Pós-Graduação em Cognição e Linguagem, Campos dos Goytacazes-RJ, Brasil. ORCID: https://orcid.org/0000-0002$\underline{5248-7733}$
\end{abstract}

\begin{abstract}
Resumo
Introdução. O zumbido é uma percepção subjetiva do som na ausência de estímulo acústico externo. Tem impactos comportamentais negativos associados, por exemplo, depressão, insônia, dificuldade de concentração, ansiedade, irritabilidade e pânico. As sensações interferem negativamente na vida social e econômica dos indivíduos. Dados empíricos sugerem que distúrbios no córtex auditivo e suas vias neurais dão origem a ativações espontâneas anormais associadas ao zumbido. Compreender as causas é uma tarefa desafiadora. No entanto, a hipótese atual sugere que clusters de redes neurais e sub-redes estão envolvidos na geração do zumbido. A neuroplasticidade dinâmica central induzida por uma perda periférica da entrada auditiva pode causar zumbido. Até o momento, não há um consenso amplo sobre a terapia mais eficaz para o tratamento do zumbido. Objetivo. Refletir sobre duas terapias de zumbido: Terapia de Retreinamento de Zumbido (TRT) e Estimulação Magnética Transcraniana (TMS). Método. Uma revisão narrativa. Não foram adotados critérios explícitos e sistemáticos na busca do referencial teórico. Resultados. A TMS é promissora em comparação com a TRT porque a TMS atua nos mecanismos neurais do zumbido. TRT é eficaz em um nível comportamental, uma vez que alivia os sentimentos negativos do zumbido leve e moderado. Conclusão. O TRT não avança na fonte neural, mas apenas na percepção do zumbido. O TMS atua diretamente nas causas neurais. Ambas as terapias têm limitações e podem funcionar para alguns pacientes. No entanto, o efeito do TMS parece mais eficiente, embora transitório.
\end{abstract}

Unitermos. Terapia de retreinamento do zumbido; Estimulação magnética transcraniana; Córtex auditivo; Neurociência

\footnotetext{
Abstract

Introduction. Tinnitus is a subjective perception of sound in the absence of an external acoustic stimulus. It has negative behavioral feelings associated, e.g., depression, insomnia, difficulty of concentration, anxiety, irritability, and panic. The feelings impact negatively on the social and economic life of individuals. Empirical data suggest that disorders in the auditory cortex and its neural pathways give rise to abnormal spontaneous activations associated with tinnitus. Understanding the causes remains challenging. However, the current hypothesis suggests that clusters of neural networks and subnetworks are involved in tinnitus generation. Central dynamic neuroplasticity induced by a peripheral loss of auditory input can cause tinnitus noise. To date, there is no widespread consensus about the most effective therapy for treating tinnitus. Objective. To reflect on two tinnitus therapies: Tinnitus Retraining Therapy (TRT) and Transcranial Magnetic Stimulation (TMS). Method. A narrative review. Explicit and systematic criteria were not adopted in searching for the theoretical framework. Results. TMS
} 
is promising compared to TRT because TMS acts on tinnitus neural mechanisms. TRT is effective on a behavioral level since it relieves mild and moderate tinnitus' negative feelings. Conclusion. TRT does not advance on the neural source, but only on the tinnitus perception. TMS acts directly on the neural causes. Both therapies have limitations and can work for some patients. However, the effect of TMS seems more efficient, although transient.

Keywords. Tinnitus Retraining Therapy; Transcranial Magnetic Stimulation; Auditory Cortex; Neuroscience

\section{Resumen}

Introducción. El tinnitus es una percepción subjetiva del sonido en ausencia de estímulos acústicos externos. Tiene sentimientos negativos asociados, por ejemplo, depresión, insomnio, dificultad para concentrarse, ansiedad, irritabilidad y pánico. Los sentimientos impactan negativamente en la vida social y económica de las personas. Los datos empíricos sugieren que los trastornos en la corteza auditiva y sus vías neurales dan lugar a activaciones espontáneas anormales asociadas con el tinnitus. Comprender las causas sigue siendo un desafío. Sin embargo, la hipótesis actual sugiere que grupos de redes neuronales y subredes están involucrados en la generación de tinnitus. La neuroplasticidad dinámica central inducida por una pérdida periférica de entrada auditiva puede causar ruido de tinnitus. Hasta la fecha, no existe un consenso generalizado sobre la terapia más eficaz para tratar el tinnitus. Objetivo. Reflexionar sobre dos terapias para el tinnitus: la terapia de reentrenamiento para el tinnitus (TRT) y la estimulación magnética transcraneal (TMS). Método. Una revisión narrativa. No se adoptaron criterios explícitos y sistemáticos en la búsqueda del marco teórico. Resultados. TMS es prometedor en comparación con TRT porque TMS actúa sobre los mecanismos neurales del tinnitus. La TRT es eficaz a nivel conductual, ya que alivia los sentimientos negativos del tinnitus leve y moderado. Conclusión. TRT no avanza en la fuente neural, sino solo en la percepción del tinnitus. TMS actúa directamente sobre las causas neuronales. Ambas terapias tienen limitaciones y pueden funcionar para algunos pacientes. Sin embargo, el efecto de TMS parece más eficiente, aunque transitorio.

Palabras clave. Terapia de reentrenamiento de tinnitus; Estimulación magnética transcraneal; Corteza auditiva; Neurociencia

Research developed at Universidade Estadual do Norte Fluminense Darcy Ribeiro (UENF), Campos dos Goytacazes-RJ, Brasil.

Corresponding author: Carlos Eduardo B. de Sousa. Universidade Estadual do Norte Fluminense Darcy Ribeiro. Centro de Ciências do Homem, Laboratório de Cognição e Linguagem. Av. Alberto Lamego 2.000, $\mathrm{CCH}$, sala 102. CEP 28013-602. Campos dos Goytacazes-RJ. Brasil. Tel.: +55-22-2748-6455. Email: cdesousa@uenf.br

\section{INTRODUCTION}

\section{Tinnitus is the sensation of sound without physical} stimulation. Recently it was reconceptualized as a conscious perception of sound in the absence of an external acoustic stimulus $^{1-3}$. It is a complex disorder with numerous forms and different causes. The concept of tinnitus originates from the Latin word tinnire, meaning to ring. 
Tinnitus divides into two categories: objective, generated by corporal vascular processes or muscle contractions, and subjective. Subjective tinnitus is most frequent, though it cannot be measured by objective means. The patient's reports are the only source available.

The bothersome sensation of tinnitus is present in several groups in the world. Between 5 and $15 \%$ of the general population experience this phantom auditory sensation and 1-3\% suffer from severe tinnitus ${ }^{4}$. In Brazil, São Paulo, the frequency of tinnitus is estimated between $10-15 \%$ of the general adult population ${ }^{5}$. In China, about $15 \%$ of the Chinese population suffers from tinnitus ${ }^{6}$. However, only $3-5 \%$ of $10-15 \%$ is considered tractable in clinical terms?.

Patients with tinnitus suffer from anxiety and depression ${ }^{2,8,9}$. Further, negative effects are reported, e.g., insomnia, difficulty of concentration, irritability, and panic. The harmful feelings impact negatively on the social and economic life of individuals $2,8,10,11$.

Despite doubts concerning the source of tinnitus, the sound is different from any known sound. It can be intermittent or continuous, and people usually describe their tinnitus as annoying, irritating, intrusive, and distracting.

The patient's frequent complaint is the negative feeling toward the sound. Some patients hear their tinnitus as if it came from the ears; others hear it as if it came from inside the head. Yet, patients tend to describe their tinnitus as ringing, hissing, cycads, roaring ${ }^{9}$. 
The single criterion for tinnitus evaluation is the patient's perception and report. The intensity of the tinnitus perception varies from person to person, and it is classified as mild, moderate, and severe. An alternative classification was proposed: (i) acute and chronic, (ii) decompensated and compensated $^{12}$. The first refers to the duration and persistence of tinnitus (at least 3 months), the second is related to the degree of habituation to the tinnitus process. Moreover, the intensity can range from a just noticeable hissing sound to a roaring noise that affects daily life, e.g., sleep, concentration, and several other activities.

This paper discusses two therapies for treating tinnitus: TRT and the potential effect of Transcranial magnetic stimulation (TMS). We consider issues concerning both treatments. We summarized the main positions about the topic.

\section{METHOD}

To achieve the objectives, we conducted a literature review on the subject. The focus was on books and texts available on the Google Scholar database since it covers a range of databases. We selected papers that reported studies with TRT or TMS. Moreover, we included texts by their originality and impact on the topic.

We extended the references with the standard texts back in time and added recent research to give support to our reflection. Since it is a narrative review, explicit and 
systematic criteria were not adopted in searching for the theoretical framework. Finally, we made a critical assessment by considering the positive and negative aspects of TMS and TRT therapies.

\section{RESULTS}

Auditory cortex: the possible source of tinnitus perception?

Tinnitus is a complex disorder because of the etiological heterogeneity. The disorder can be caused by several factors ${ }^{4,13,14}$. The multiple causal aspects make the treatment challenging. So far, the known possible causes of tinnitus divide into five groups: (1) otologic: hearing loss, Meniere's disease, acoustic neuroma; (2) ototoxic: medications or substances; (3) neurologic: multiple sclerosis, head injuries; (4) metabolic: thyroid disorder, hyperlipidemia, vitamin B12 deficiency; and (5) psychogenic: depression, anxiety, fibromyalgia ${ }^{15,16}$.

Despite many years of intensive research, there is no compelling agreement concerning the cause of tinnitus ${ }^{9,17}$. There are even doubts whether tinnitus is generated in the ears or the head ${ }^{3}$. However, pioneer studies discovered and converged to some extent that the conscious perception of tinnitus results from abnormal neuronal activities in the auditory cortex and its subnetworks ${ }^{18-22}$.

Studies have shown that tinnitus experience is associated with functional and structural changes at the neural level23-30. Neurophysiological tools could signal the 
source of tinnitus. With this in mind, empirical finds suggest that the auditory cortex is the possible basis, where the neural stimuli are transformed into a subjective sensation.

Besides, disorders of the somatosensory system and abnormal neural activities are related to the generation of tinnitus ${ }^{2,12,31}$. As far as can be seen, there is an agreement that tinnitus is neurally realized. However, the difficulty is the accurate identification of the neural correlates of tinnitus ${ }^{32}$. Since brains are adaptive systems with several levels of interconnections, the task of identifying the correct neuronal networks mainly active during the experience of tinnitus is challenging.

Some data suggest that tinnitus can be caused by maladaptive neuroplasticity and deafferentation of auditory neural pathway ${ }^{19,33-36}$. The changes (triggered by several factors, e.g., physical injuries) give rise to abnormal spontaneous activity in the auditory cortex, abnormal neurotransmitter release, abnormalities in the transduction processes, cortical reorganization of the tonotopic sensory map, hypersynchrony of neural discharges, and enhanced sensitivity of the auditory pathways ${ }^{3}$. Further empirical finds from neuroimaging suggest that tinnitus is related to functional and structural brain abnormalities in distributed auditory and non-auditory brain regions ${ }^{22,37 .}$

Nonetheless, the functional organization of the human auditory cortex remains unclear. To this point, there is no complete map of the auditory system ${ }^{38}$. The recent knowledge is based on post mortem anatomy, studies of 
patients with cerebral lesions, as well as results from noninvasive anatomical and functional brain-imaging methods, like functional magnetic resonance imaging (fMRI), positron emission tomography (PET), electroencephalography (EEG), and magnetoencephalography (MEG) ${ }^{39}$.

Hence, it is difficult to match the anatomical parcellation of the human auditory cortex with the loci of functional activation. Not even the exact borders and the tonotopic organization of the human primary auditory cortex have been shown convincingly yet ${ }^{40}$.

There is a difficulty in the identification of tinnitus etiology. However, there are therapies and treatments which aim to relieve such negative sensation produced by tinnitus. One is the TRT $8,10,14,41$, a clinical implementation with a focus on the habituation of tinnitus signal noise. The other therapy that emerges as an alternative, is TMS. However, both have issues to take into account.

\section{Tinnitus retraining therapy}

TRT can be clinically implemented as an attempt to relieve the tinnitus perception ${ }^{8,10,14,41}$. TRT is based on two properties of the brain: plasticity and habituation. Two main systems in the brain play central roles: the limbic and the autonomic nervous systems. TRT aims to induce changes in these systems by removing the association of tinnitus with negative feelings. The core idea is that the limbic system regulates tinnitus perception. Therefore, it can be modulated by a specific intervention. 
Misophonia (aversion to sound) is also a frequent symptom in patients with tinnitus since they have a negative attitude toward sounds. Some studies showed a relationship between negative feelings and the activation of the limbic system ${ }^{42}$.

The limbic system regulates several functions e.g., emotion, behavior, motivation, long-term memory, and olfaction. The limbic system also controls the emotional life. Any dysfunction in this area correlates with episodes of emotional instability. As tinnitus has an emotional factor, induced changes in the limbic system can lessen tinnitus perception $8,10,14,41$.

TRT treatment consists of two main methods: counseling and sound therapy. The goal is to reclassify tinnitus into the category of a "neutral stimulus". The tinnitus perception and its evaluation rest on the inappropriate activations of the limbic and sympathetic parts of the autonomic nervous system. The massive brain interconnectivity is supposed to cause the association of the negative feelings toward tinnitus perception. TRT induces changes in the evaluation of the perception through modulation of the negative feelings. The focus is on the perception itself, instead of the source of the tinnitus.

Sound therapy aims to stimulate the auditory system with the presence of constant neutral sounds (music or white noise). Sound generators are used, associated or not with sound amplification (if the person also has hearing loss). During the process, the brain is trained to reclassify the 
tinnitus through the conversion of the perceived (negative) sound into an unimportant sound (neutral). As result, the annoying sound drifts away until the subject becomes unaware of it $8,10,14,41$.

Furthermore, TRT includes counseling therapy by showing to the patients how the auditory system works and how tinnitus is generated: the neural signals generated in the auditory cortex reach the limbic system, and there, the perception receives a negative evaluation. The effect is the amplification of subjective sensation immediately sensed after the subject becomes aware of the tinnitus perception. The discomfort arises when the subject focuses attention on that perception. Then, the negative attitude toward tinnitus arises.

During TRT sessions, the patient can become accustomed to the tinnitus signal until its perception changes to neutral. The counseling sessions consist of teaching the patient to reclassify his/her tinnitus into the category of "neutral stimulus". Counseling consists of saying to patients that tinnitus is not a harmful perception, but a benign reaction (adaptation) of the auditory system to compensate for the damage of the outer hair cell systems.

Given the brain's capacities of plasticity and habituation, TRT can change the evaluation of the tinnitus, and the perception would become neutral. The key element causing the tinnitus to be problematic is not the perception of tinnitus itself, but the focus on attention on this 
perception. Despite the effectiveness of clinical treatment, the etiology, cause, or trigger of tinnitus remains unknown ${ }^{10}$. Indeed, there is an urgent demand for an effective treatment for tinnitus. TRT seems to be an effective therapy. It was reported ${ }^{8}$ that various patients regained a better quality of life after TRT treatment. However, TRT seems to relieve only mild and significant tinnitus. TRT does not seem to work for the treatment of chronic or severe tinnitus.

The assumption that people with severe hearing loss and tinnitus can become habituated with the "neutral" sound is controversial. Neutral sounds can reach high intensities and can cause discomfort. Loud sounds can be so high that bother other people. Furthermore, high sound (noise) can induce hearing loss. The treatment with TRT requires the need to listen to white noise daily. But eventually, the sound also becomes bothersome.

Regardless of the attempt to modulate the tinnitus perception, a patient might not get accustomed to the sound. Hence, the substitution of a disturbing sound by another one does not seem to be a proper treatment. A better alternative would require the complete elimination of the tinnitus. Likewise, counseling, and sound therapy can work in a few specific cases.

TRT seems suitable for the treatment of mild tinnitus. The idea that the limbic system triggers negative feelings toward the tinnitus perception is self-evident. The limbic system must be active during emotional evaluations. The assumption that a causal mechanism generating tinnitus is 
irrelevant, is problematic. Likewise, assuming that a cure for tinnitus is impossible since there is a large number of causes is elusive. The fact that tinnitus has many causes does not imply that it has no causal trigger. Theoretically, it would be possible to track the source by using tools as EEG/MEG and neuroimaging techniques $22,43-46$. The search for the neurobiological causes of tinnitus is a hot research topic.

Moreover, TRT does not take into account the neuronal activities underlying tinnitus perception. In short, plasticity, as well as habituation, are neural events. Mere behavioral therapy does not seem to act directly on neural activities, although it can happen occasionally. Furthermore, criticisms of TRT point out the lack of convincing empirical support for it ${ }^{47}$ and doubts about the efficacy of counseling and sound therapy ${ }^{48}$.

The final consideration is that TRT leaves the problem open, since it does not attack the cause, but the symptom. Noticeably, some patients can benefit from TRT, though it would be fair to inform them that TRT is not a cure for tinnitus. Concerning this point, De Ridder, in comments on Jastreboff's paper ${ }^{41}$, compares TRT with the following situation:

"A child hurting himself and being helped by his caretaker. Immediately after the injury the child is told 'it doesn't hurt' and the painful spot is being kissed or rubbed. This is what TRT does as well: when the child is told it doesn't hurt, the child's caretaker reclassifies the sensory perception of pain into the category of neutral stimuli, similarly to what the healthcare worker does when counseling in TRT." 
The kissing or rubbing on the painful spot applies the same principles as sound therapy for tinnitus. The therapy decreases the contrast between the perceived pain and the background neural activity, thus interfering with the brain's ability to detect the painful signal. Furthermore, the treatment reconditions the pain perception with a positive reinforcer, a kiss, or any other sign of affection. However, this "hush and kiss" approach seems to be efficient only for moderate pain; failing to do so when a leg is broken, a tumor is found, etc. Analogously, the autosuggestion effect of TRT has limits.

Moreover, TRT lacks problem-solving because it does not tackle the tinnitus generating source. Behavioral therapy based on counseling and sound therapy indeed could change neuronal activities associated with the generation of tinnitus. However, it takes time. Neurons communicate through electrochemical synapses that can be interfered with by using direct electromagnetic stimulation in the sensory cortex and other deep areas.

Up to now, there is no objective method of evaluation of tinnitus. Even though the acquisition of "data" through the patient's reports, which are subjective and work as support for medical diagnostic, raises a concern about reliability. Furthermore, the etiological heterogeneity makes difficult the choice of proper therapy. 


\section{Transcranial magnetic stimulations as an alternative treatment}

TMS is a non-invasive tool for brain stimulation. The technique consists of applying a brief pulse of high-intensity magnetic field on the auditory cortex by $100 \mathrm{~ms}$. The electromagnetic field can excite or inhibit a small area, previously selected, after identifying specific regions through EEG and fMRI. During the procedure, tinnitus signals decrease or disappear, but the effects are temporary $43,49-51$.

TMS is used in the direct modulation of neuronal activities. Neuronal activations in the auditory cortex generate the tinnitus subjective experience. However, it could not be the tinnitus primary source. Nonetheless, the auditory cortex should be active. TMS can change the frequency of activities in the auditory cortex, although which neural pathways should be stimulated, is still undetermined. The difficult task is to locate the causal area.

Notwithstanding the etiological source, the abnormal neuronal activities in the auditory cortex are supposed to be the active locus during the tinnitus experience. In this way, this region could be modulated with TMS $44,52-55$. TMS application aims at the elimination of the phantom perception, instead of the habituation to the bothersome tinnitus. TMS induces changes in the neural activations associated with tinnitus perception.

TMS is an experimental tool and it requires further studies. However, it seems effective since TMS acts directly 
on specific brain areas by changing its neuronal frequencies. Empirical support is available as follows.

Repetitive TMS (rTMS) of $1 \mathrm{~Hz}$ was applied daily for 10 consecutive workdays in 64 participants with chronic tinnitus ${ }^{56}$. The 64 participants were divided into two groups: a control group treated with placebo (no active TMS); and an active group. The participants from the active group received 2000 rTMS pulses per session. The Tinnitus Functional Index (TFI) was used as a comparative baseline. The results showed 18 of 32 participants (56\%) in the active rTMS group and 7 of 32 participants (22\%) in the placebo rTMS group were responders to rTMS treatment. In other words, 10 consecutive workdays resulted in a significantly statistically greater percentage of responders to the treatment in the active rTMS group compared to the placebo group. The active group reported noteworthy relief after the treatment of rTMS. Responders experienced improvements in tinnitus severity for 26 weeks following therapy.

In another experiment, an individualized rTMS in 25 tinnitus patients was conducted ${ }^{57}$. During the first session of a 2-week rTMS protocol, they applied different rTMS protocols to the left and right temporo-parietal and dorsolateral prefrontal cortex. The results depicted that almost half of the patients (12 of 25 ) reported immediate tinnitus reductions during the test session. This group had higher improvement mean values (medium to high effect rates) in pre- to post-treatment, based on the tinnitus questionnaire, when contrasted to the patients who did not 
respond to the test session. The treatment outcome remained stable over a follow-up period of 10 weeks. According to the authors ${ }^{57}$ :

\begin{abstract}
"Individualized rTMS was shown to be feasible and effective in chronic tinnitus. The results obtained from this study provide tentative evidence in support of an individualized rTMS treatment approach and might provide a basis for a "tailored" application of rTMS in tinnitus and other neuropsychiatric disorders."
\end{abstract}

Other studies confirm the hypotheses that TMS can be an efficient treatment for chronic tinnitus. For example, it was reported that daily application of high-intensity $1-\mathrm{Hz}$ rTMS to the left temporoparietal region is an efficient strategy to transiently alleviate chronic tinnitus ${ }^{45}$. Further studies $^{55}$ found that tinnitus loudness was reduced after temporoparietal stimuli. Also, it was reported that some patients showed a lasting benefit of tonic rTMS $(1,10$, or 25 $\mathrm{Hz}$ ) applied for 10 days at 1 year after treatment conclusion $^{58}$. Another study described improvement after 5 days of rTMS at $1 \mathrm{~Hz}$ that was still present 6 months post$\mathrm{TMS}^{59}$.

Likewise, a statistically significant greater percentage of responders to treatment in the active rTMS group compared with the placebo rTMS group in an experiment with 32 participants was reported ${ }^{60}$. In sum, TMS showed effective effects on treatment for chronic tinnitus. Although the 
mitigation seems to be transient, TMS offers a real perspective to be developed.

However, the studies have a few limitations concerning the number of participants (up to 100). The sample sizes are small, and the placebo group presented a degree of decrease in the tinnitus signal. Furthermore, different regions of stimulation turn the task to compare experiments difficult ${ }^{45}$. Moreover, there are additional protocol issues (e.g., methodological plurality, small sample size, size effect, scarce reproducibility $)^{61-65}$.

Despite this, the studies reported that the application of TMS was effective in tinnitus relief. The challenging task is to induce long-duration after-effects since the result is transient. The nature of the rTMS after-effects depends on the number, intensity, and frequency of stimulation pulses, a task whose settings are still challenging.

\section{CONCLUSION}

In sum, TRT does not seem a suitable treatment for chronic tinnitus, since it tackles the symptoms, rather than the cause. TRT can be useful in treating mild cases. TRT is not recommended when the patient has severe or chronic tinnitus.

The research should focus on the neuronal basis underlying the tinnitus experience. Through the identification of the neural mechanisms active during the tinnitus perception, researchers and clinicians can apply effective 
tools such as TMS associated with FMRI, MEG, and EEG to track the etiology.

The utilization of TMS seems to be more effective in comparison to the TRT. TMS acts on the neural source. However, the after-effect of TMS is temporary and this is a challenge in TMS therapy. Besides, there are doubts concerning how to set a methodological account that could make the relief last longer, since, after the TMS sessions, the phantom perception returns. Despite this experimental constraint, there are prospects in the attempt to find a solution for the tinnitus problem in a neuroscientific way ${ }^{66}$.

In summary, TMS still has a transitory effect on tinnitus, but this is due to the lack of knowledge concerning the cortical sensory area TMS should be applied, the duration, intensity, and frequency of the stimuli. TMS is a new tool that needs further investigation. Nonetheless, it is the beginning of a new phase in tinnitus research, from which tinnitus patients can benefit in the future.

TRT is a beneficial therapy for mild tinnitus, but as a solution for severe or chronic tinnitus, it is inappropriate. TMS seems to be promising, however, there are issues to be solved. Despite the limitations, both therapies have advantages in treating types of tinnitus disorder: half a loaf is better than none.

\section{REFERENCES}

1.National Research Council (US) Committee on Hearing, Bioacoustics, and Biomechanics. Tinnitus: Facts, Theories, and Treatments. McFadden D, editor. Washington (DC): The National Academies Press; 1982. https://doi.org/10.17226/81 
2.Eggermont JJ. Pathophysiology of tinnitus. Progr Brain Res 2007;543:19-35. https://doi.org/10.1016/S0079-6123(07)66002-6 3.Eggermont JJ, Roberts LE. The neuroscience of tinnitus. Trends Neurosci 2004;27:676-82. https://doi.org/10.1016/j.tins.2004.08.010

4. Heller AJ. Classification and epidemiology of tinnitus. Otolaryngol Clin North Am 2003;36:239-48. https://doi.org/10.1016/s00306665(02)00160-3

5. Oiticica Jeanne, Bittar RSM. Tinnitus prevalence in the city of São Paulo. Braz J Otorhinolaryngol 2015;81:167-76.

https://doi.org/10.1016/j.bjorl.2014.12.004

6. Yang $H$, Cai $Y$, Guo $H$, Xiong $H$, Sun $Y$, Huang $X$, et al. Prevalence and factors associated with tinnitus: data from adult residents in Guangdong province, South of China. Int J Audiol 2018;57:898-905. https://doi.org/10.1080/14992027.2018.1506169

7.Pilgram M, Rychlik R, Lebisch $H$, Goebel $G$ KD. Tinnitus in der Bundesrepublik Deutschland. Eine repräsentative epidemiologische studie. HNO 1999; 7:261-5.

8.Jastreboff PJ. 25 Years of tinnitus retraining therapy. HNO 2015;63:307-11. https://doi.org/10.1007/s00106-014-2979-1

9.Møller AR. Hearing: Anatomy, Physiology, and Disorders of the Auditory System. Third Edition. San Diego: Plural Publishing Incorporated; 2012.

10.Jastreboff PJ, Hazell JWP. Tinnitus Retraining Therapy: Implementing the Neurophysiological Model. Cambridge: Cambridge University Press; 2004. https://doi.org/10.1017/CBO9780511544989 11.Niemann $U$, Brueggemann $P$, Boecking $B$, Mebus W, Rose $M$, Spiliopoulou $M$, et al. Phenotyping chronic tinnitus patients using selfreport questionnaire data: cluster analysis and visual comparison. Sci Rep 2020;10:16411. https://doi.org/10.1038/s41598-020-73402-8 12. Hesse G. Evidence and evidence gaps in tinnitus therapy. GMS Curr Top Otorhinolaryngol Head Neck Surg 2016;15:doc04. https://doi.org/10.3205/cto000131

13.Cederroth CR, Gallus S, Hall DA, Kleinjung T, Langguth B, Maruotti $A$, et al. Editorial: Towards an Understanding of Tinnitus Heterogeneity. Front Aging Neurosci 2019;11:53.

https://doi.org/10.3389/fnagi.2019.00053

14.Jastreboff PJ. Phantom auditory perception (tinnitus): mechanisms of generation and perception. Neurosci Res 1990;8:221-54. https://doi.org/10.1016/0168-0102(90)90031-9

15.Crummer RW, Hassan GA. Diagnostic approach to tinnitus. Am Fam Phys 2004;69:120-6.

https://www.aafp.org/afp/2004/0101/afp20040101p120.pdf

16.Freesmeyer WB, Fussnegger MR, Ahlers MO. Diagnostic and therapeutic-restorative procedures for masticatory dysfunctions. GMS Curr Top Otorhinolaryngol Head Neck Surg 2005;4:doc19. https://www.ncbi.nlm.nih.gov/pmc/articles/PMC3201006/pdf/CTO04-19.pdf 
17.König $R$, Heil $P$, Budinger $E$, Scheich $H$. The auditory cortex: A synthesis of human and animal research. New York: Taylor \& Francis; 2005; 493p.

18.Weisz N, Moratti S, Meinzer M, Dohrmann K, Elbert T. Tinnitus Perception and Distress Is Related to Abnormal Spontaneous Brain Activity as Measured by Magnetoencephalography. PLOS Med 2005;2:e153. https://doi.org/10.1371/journal.pmed.0020153

19. Weisz N, Müller S, Schlee W, Dohrmann K, Hartmann T, Elbert T. The Neural Code of Auditory Phantom Perception. J Neurosci 2007;27:1479-84. https://doi.org/10.1523/JNEUROSCI.3711$\underline{06.2007}$

20.Noreña AJ, Eggermont JJ. Changes in spontaneous neural activity immediately after an acoustic trauma: implications for neural correlates of tinnitus. Hear Res 2003;183:137-53. https://doi.org/10.1016/S0378-5955(03)00225-9

21. De Ridder D, Vanneste S, Weisz N, Londero A, Schlee W, Elgoyhen $A B$, et al. An integrative model of auditory phantom perception: Tinnitus as a unified percept of interacting separable subnetworks. Neurosci Biobehav Rev 2014;44:16-32.

https://doi.org/10.1016/j. neubiorev.2013.03.021

22.Elgoyhen $A B$, Langguth $B$, De Ridder $D$, Vanneste S. Tinnitus: perspectives from human neuroimaging. Nat Rev Neurosci 2015;16:632-42. https://doi.org/10.1038/nrn4003

23. Mühlau M, Rauschecker JP, Oestreicher E, Gaser C, Röttinger M, Wohlschläger AM, et al. Structural Brain Changes in Tinnitus. Cereb Cortex 2006;16:1283-8. https://doi.org/10.1093/cercor/bhj070

24.Schneider P, Andermann M, Wengenroth M, Goebel R, Flor H, Rupp $A$, et al. Reduced volume of Heschl's gyrus in tinnitus. Neuroimage 2009;45:927-39. https://doi.org/10.1016/j. neuroimage.2008.12.045 25. Husain FT, Medina RE, Davis CW, Szymko-Bennett Y, Simonyan K, Pajor NM, et al. Neuroanatomical changes due to hearing loss and chronic tinnitus: A combined VBM and DTI study. Brain Res 2011;1369:74-88. https://doi.org/10.1016/j.brainres.2010.10.095

26. Leaver AM, Renier L, Chevillet MA, Morgan S, Kim HJ, Rauschecker JP. Dysregulation of Limbic and Auditory Networks in Tinnitus. Neuron 2011;69:33-43. https://doi.org/10.1016/j.neuron.2010.12.002

27. Aldhafeeri FM, Mackenzie I, Kay T, Alghamdi J, Sluming V. Neuroanatomical correlates of tinnitus revealed by cortical thickness analysis and diffusion tensor imaging. Neuroradiology 2012;54:88392. https://doi.org/10.1007/s00234-012-1044-6

28.Schecklmann M, Lehner A, Poeppl TB, Kreuzer PM, Rupprecht R, Rackl J, et al. Auditory cortex is implicated in tinnitus distress: a voxelbased morphometry study. Brain Struct Funct 2013;218:1061-70. https://doi.org/10.1007/s00429-013-0520-z

29.Boyen K, Langers DRM, de Kleine E, van Dijk P. Gray matter in the brain: Differences associated with tinnitus and hearing loss. Hear Res 2013;295:67-78. https://doi.org/10.1016/j.heares.2012.02.010 
30.Adjamian P, Hall DA, Palmer AR, Allan TW, Langers DRM. Neuroanatomical abnormalities in chronic tinnitus in the human brain. Neurosci Biobehav Rev 2014;45:119-33.

https://doi.org/10.1016/j.neubiorev.2014.05.013

31.Levine RA, Abel $M$, Cheng $H$. CNS somatosensory-auditory interactions elicit or modulate tinnitus. Exp Brain Res 2003;153:6438. https://doi.org/10.1007/s00221-003-1747-3

32. Middleton J, Tzounopoulos T. Imaging the neural correlates of tinnitus: a comparison between animal models and human studies. Front Syst Neurosci 2012;6:35.

https://doi.org/10.3389/fnsys.2012.00035

33. Mühlnickel W, Elbert T, Taub E, Flor H. Reorganization of auditory cortex in tinnitus. Proc Natl Acad Sci USA 1998;95:10340-3. https://doi.org/10.1073/pnas.95.17.10340

34.Schlee W, Weisz N, Dohrmann K, Hartmann T, Elbert T. Unravelling the tinnitus distress network using single trial auditory steady-state responses. Int Congr Ser 2007;1300:73-6.

https://doi.org/10.1016/j.ics.2006.12.059

35.Schlee W, Weisz N, Bertrand O, Hartmann T, Elbert T. Using Auditory Steady State Responses to Outline the Functional Connectivity in the Tinnitus Brain. PLoS One 2008;3:e3720.

https://doi.org/10.1371/journal.pone.0003720

36.Wu C, Stefanescu RA, Martel DT, Shore SE. Tinnitus: Maladaptive auditory-somatosensory plasticity. Hear Res 2016;334:20-9. https://doi.org/10.1016/j. heares.2015.06.005

37. Maudoux A, Lefebvre P, Cabay J-E, Demertzi A, Vanhaudenhuyse $A$, Laureys $S$, et al. Connectivity graph analysis of the auditory resting state network in tinnitus. Brain Res 2012;1485:10-21. https://doi.org/10.1016/j.brainres.2012.05.006

38. Howard MA, Volkov IO, Mirsky R, Garell PC, Noh MD, Granner M, et al. Auditory cortex on the human posterior superior temporal gyrus. J Comp Neurol 2000;416:79-92. https://doi.org/10.1002/(SICI)10969861(20000103)416:1<79::AID-CNE6>3.0.CO;2-2

39.Lanting CP, de Kleine E, van Dijk P. Neural activity underlying tinnitus generation: Results from PET and fMRI. Hear Res 2009;255:113. https://doi.org/10.1016/j.heares.2009.06.009

40.Warren J (reviwed). The Auditory Cortex, A Synthesis of Human and Animal Research. J Neurol Neurosurg Psychiatr 2005;76:1746. https://doi.org/10.1136/jnnp.2005.071746

41.Jastreboff PJ, Jastreboff MM. Tinnitus Retraining Therapy: A Different View on Tinnitus. ORL 2006;68:23-30.

https://doi.org/10.1159/000090487

42.Besteher B, Gaser C, Ivanšić D, Guntinas-Lichius O, Dobel C, Nenadić I. Chronic tinnitus and the limbic system: Reappraising brain structural effects of distress and affective symptoms. NeuroImage Clin 2019;24:101976. https://doi.org/10.1016/j.nicl.2019.101976

43. De Ridder D, Verstraeten E, Van der Kelen K, De Mulder G, Sunaert S, Verlooy J, et al. Transcranial Magnetic Stimulation for Tinnitus: Influence of Tinnitus Duration on Stimulation Parameter Choice and 
Maximal Tinnitus Suppression. Otol Neurotol 2005;26:616-9. https://doi.org/10.1097/01.mao.0000178146.91139.3c

44.Eichhammer P, Langguth B, Marienhagen J, Kleinjung T, Hajak G. Neuronavigated repetitive transcranial magnetic stimulation in patients with tinnitus: A short case series. Biol Psychiatr 2003;54:862-5. https://doi.org/10.1016/S0006-3223(02)01896-6

45.Ciminelli P, Machado S, Nardi AE. Repetitive Transcranial Magnetic Stimulation and Tinnitus-Still a Noisy IssueRepetitive Transcranial Magnetic Stimulation and TinnitusLetters. JAMA Otolaryngol Neck Surg 2016;142:194-5. https://doi.org/10.1001/jamaoto.2015.2954

46. Sanchez TG, Valim CCA, Schlee W. Long-lasting total remission of tinnitus: A systematic collection of cases. Chapter 13. Progress Brain Res 2021;260:269-82. https://doi.org/10.1016/bs.pbr.2020.05.023

47.Kroener-Herwig B, Biesinger E, Gerhards F, Goebel G, Greimel KV, Hiller W. Retraining therapy for chronic tinnitus. A critical analysis of its status. Scand Audiol 2000;29:67-78.

https://doi.org/10.1080/010503900424471

48. Wilson PH, Henry JL, Andersson G, Hallam RS, Lindberg P. A Critical Analysis of Directive Counselling as a Component of Tinnitus Retraining Therapy. Br J Audiol 1998;32:273-86.

https://doi.org/10.3109/03005364000000078

49. De Ridder D, De Mulder G, Verstraeten E, van der Kelen K, Sunaert $\mathrm{S}$, Smits $\mathrm{M}$, et al. Primary and Secondary Auditory Cortex Stimulation for Intractable Tinnitus. ORL 2006;68:48-55. https://doi.org/10.1159/000090491

50.Rossi S, Ferro M, Cincotta M, Ulivelli M, Bartalini S, Miniussi C, et al. A real electro-magnetic placebo (REMP) device for sham transcranial magnetic stimulation (TMS). Clin Neurophysiol 2007;118:709-16. https://doi.org/10.1016/j.clinph.2006.11.005

51.Theodoroff SM, Griest SE, Folmer RL. Transcranial magnetic stimulation for tinnitus: using the Tinnitus Functional Index to predict benefit in a randomized controlled trial. Trials 2017;18:64. https://doi.org/10.1186/s13063-017-1807-9

52.Khedr EM, Rothwell JC, Ahmed MA, El-Atar A. Effect of daily repetitive transcranial magnetic stimulation for treatment of tinnitus: Comparison of different stimulus frequencies. J Neurol Neurosurg Psychiatry 2008;79:212-5.

http://dx.doi.org/10.1136/jnnp.2007.127712

53. Kleinjung $T$, Eichhammer $P$, Langguth $B$, Jacob P, Marienhagen J, Hajak G, et al. Long-term effects of repetitive transcranial magnetic stimulation (rTMS) in patients with chronic tinnitus. Otolaryngol Head Neck Surg 2005;132:566-9.

https://doi.org/10.1016/j.otohns.2004.09.134

54.Plewnia C, Bartels M, Gerloff C. Transient suppression of tinnitus by transcranial magnetic stimulation. Ann Neurol 2003;53:263-6. https://doi.org/10.1002/ana.10468

55.Plewnia C, Reimold M, Najib A, Brehm B, Reischl G, Plontke SK, et al. Dose-dependent attenuation of auditory phantom perception 
(tinnitus) by PET-guided repetitive transcranial magnetic stimulation. Hum Brain Mapp 2007;28:238-46.

https://doi.org/10.1002/hbm.20270

56. Folmer RL, Theodoroff SM, Casiana L, Shi Y, Griest S, Vachhani J. Repetitive transcranial magnetic stimulation treatment for chronic tinnitus: A randomized clinical trial. JAMA Otolaryngol Head Neck Surg 2015;141:716-22. https://doi.org/10.1001/jamaoto.2015.1219

57.Kreuzer PM, Poeppl TB, Rupprecht R, Vielsmeier V, Lehner A, Langguth $\mathrm{B}$, et al. Individualized Repetitive Transcranial Magnetic Stimulation Treatment in Chronic Tinnitus? Front Neurol 2017;8:126. https://doi.org/10.3389/fneur.2017.00126

58.Khedr EM, Rothwell JC, El-Atar A. One-year follow up of patients with chronic tinnitus treated with left temporoparietal rTMS. Eur J Neurol 2009;16:404-8. https://doi.org/10.1111/j.14681331.2008.02522.x

59.Marcondes RA, Sanchez TG, Kii MA, Ono CR, Buchpiguel CA, Langguth $B$, et al. Repetitive transcranial magnetic stimulation improve tinnitus in normal hearing patients: a double-blind controlled, clinical and neuroimaging outcome study. Eur J Neurol 2010;17:38-44. https://doi.org/10.1111/j.1468-1331.2009.02730.

60.Piccirillo JF. Transcranial Magnetic Stimulation for Chronic TinnitusTranscranial Magnetic Stimulation for Chronic TinnitusTranscranial Magnetic Stimulation for Chronic Tinnitus. JAMA 2016;315:506-7. https://doi.org/10.1001/jama.2016.0075

61. Kotchoubey B, Tretter F, Braun HA, Buchheim T, Draguhn A, Fuchs $\mathrm{T}$, et al. Methodological Problems on the Way to Integrative Human Neuroscience. Front Integrat Neurosci 2016;10:41. https://doi.org/10.3389/fnint.2016.00041

62.Schäfer T, Schwarz MA. The Meaningfulness of Effect Sizes in Psychological Research: Differences Between Sub-Disciplines and the Impact of Potential Biases. Front Psychol 2019;10:813. https://doi.org/10.3389/fpsyg.2019.00813

63. Button KS, Ioannidis JP, Mokrysz C, Nosek B, Flint J, Robinson ESJ, et al. Power failure: why small sample size undermines the reliability of neuroscience. Nat Rev Neurosci 2013;14:365-76. https://doi.org/10.1038/nrn3475

64. Begley CG, Ioannidis JPA. Reproducibility in science: Improving the standard for basic and preclinical research. Circ Res 2015;116:116-26. https://doi.org/10.1161/CIRCRESAHA.114.303819

65.Ioannidis JPA, Munafò MR, Fusar-Poli P, Nosek BA, David SP. Publication and other reporting biases in cognitive sciences: Detection, prevalence, and prevention. Trends Cogn Sci 2014;18:235-41. https://doi.org/10.1016/j.tics.2014.02.010

66.Baizer JS, Lobarinas E, Salvi R, Allman BL. Brain Research special issue: Advances in the neuroscience of tinnitus. Brain Res 2012;1485:1-2. https://doi.org/10.1016/j.brainres.2012.10.033 